\title{
Cytological Localization of Adenosine Kinase, Nucleoside Phosphorylase-1, and Esterase-10 Genes on Mouse Chromosome 14
}

\author{
Linda C. Samuelson ${ }^{1}$ and Rosann A. Farber \\ Department of Molecular Genetics and Cell Biology, University of Chicago, 920 E. 58 Street, Chicago, Illinois \\ 60637
}

Received 27 August 1984-Final 3 December 1984

\begin{abstract}
We have determined the regional locations on mouse chromosome 14 of the genes for mouse adenosine kinase (ADK), nucleoside phosphorylase-1 (NP-1), and esterase-10 (ES-10) by analysis of rearranged mouse chromosomes in $\gamma$-irradiated Chinese hamster $\times$ mouse hybrid cell lines. Irradiated clones were screened for expression of the murine forms of these enzymes; segregant clones that expressed only one or two of the three markers were karyotyped. The patterns of enzyme expression in these segregants were correlated with the presence of rearranged chromosomes. The Adk gene was localized to bands $A 2$ to $B, \mathrm{~Np}-1$ to bands $B$ to $C l$, and Es- 10 to bands D2 to E2.
\end{abstract}

\section{INTRODUCTION}

Although the mouse is the best characterized genetically of the experimental mammals, precise map locations have been established for only a few of the selectable genetic markers that are expressed in cultured cells. Several such loci have been assigned to specific chromosomes by cell hybridization mapping techniques, but regional map positions are not known for most of them [for map, see ref. (1)].

Parasexual mapping approaches used for regional localization of mouse genes have depended upon the availability either of mouse strains carrying informative chromosomal rearrangements (2) or of hybrid cell lines containing informative spontaneous rearrangements $(3,4)$. In particular, hybrids formed between mouse cells and one Chinese hamster cell line, $\mathrm{CHO}$, have significant frequencies of mouse chromosomal rearrangements $(4,5)$. The use of physical agents to induce chromosome breakage and rearrangement in hybrid cells has been described for the regional mapping of human genes (6-9), but a similar approach has not previously been applied to the mouse.

This report describes the cytological localization on chromosome 14 of the genes for mouse adenosine kinase (ADK), nucleoside phosphorylase (NP-1), and esterase-10 (ES-10). These three genes had previously been assigned to this chromosome $(10,11)$, and genetic map locations were known for $N p-1$ and $E s-10$, but not for $A d k(10,12)$. Cytological map locations for these genes had not been determined.

A series of hybrid cell lines carrying mouse chromosome rearrangements was gen-

\footnotetext{
${ }^{1}$ Present address: Department of Human Genetics, University of Michigan, Ann Arbor, Michigan 48109.
} 
erated by $\gamma$-irradiation of a Chinese hamster $\times$ mouse hybrid cell line. We determined the position of mouse Adk relative to the other two markers on chromosome 14 and localized all three genes to specific chromosomal regions by correlating their expression with the presence of subchromosomal fragments retained in the irradiated hybrid lines.

\section{MATERIALS AND METHODS}

Cell Culture and Cell Lines. Cells were cultured in Eagle's minimal essential medium (MEM) supplemented with $5 \%$ fetal calf serum, 5\% horse serum, penicillin (50 units/ $\mathrm{ml}$ ), and nonessential amino acids.

The CAK-B3 mouse cell line used for hybrid construction is a subclone of the CAKA32-G11 embryonic fibroblast line $(13,14)$. The hamster line is a derivative of $\mathrm{CHO}-\mathrm{K} 1$ (15) that is deficient for hypoxanthine phosphoribosyltransferase and ADK and resistant to $3.0 \mathrm{mM}$ ouabain. The hybrid 7B31a was constructed by polyethylene glycol fusion of these two lines $(16,17)$. Hybrids were selected in HAT $(0.1 \mathrm{mM}$ hypoxanthine, $0.4 \mu \mathrm{M}$ aminopterin, $16.0 \mu \mathrm{M}$ thymidine) (18) and ouabain $(3.0 \mathrm{mM})(19)$. The hybrid clone used for the mapping analysis, 7B31a-TG2b-2, is a derivative of $7 \mathrm{~B} 3 \mathrm{la}$ that lost the mouse $\mathrm{X}$ chromosome after growth in 6-thioguanine (6 $\mu \mathrm{g} / \mathrm{ml})$.

Gamma-Irradiation. Exponentially growing 7B31a-TG2b-2 hybrid cells were trypsinized, suspended in MEM with serum, and irradiated at room temperature in a model 143-35 irradiator (J.L. Shepherd and Assoc., Glendale, California) with a ${ }^{137} \mathrm{Cs}$ source at a dose rate of $300 \mathrm{rad} / \mathrm{min}$. The $D_{0}$ value (37\% survival) was approximately 500 rad. Following irradiation, cells were rinsed once in phosphate-buffered saline and plated in nonselective medium. Three days later, the plates were split into two groups. One group was maintained without selection; the other group was maintained in the presence of toyocamycin $(50 \mathrm{ng} / \mathrm{ml})$, which was a gift from $\mathrm{J}$.
Dauros, National Cancer Institute. Surviving colonies were isolated after 10-14 days.

Electrophoresis. Cell extracts were prepared at a concentration of $5 \times 10^{7}$ cells $/ \mathrm{ml}$ by the method of Nichols and Ruddle (20). NP-1 and ES-10 activities were identified on $11 \%$ starch gels according to the procedures of Womack et al. (10) and Peters and Nash (21), respectively, as described in Eves and Farber (14). ADK activity was assayed by cellogel electrophoresis using the method of Chan et al. (22).

Chromosome Analysis. Chromosomes were identified after two sequential staining procedures. Slides were first prepared and Giemsa-banded as previously described (14); they were then destained in methanol-acetic acid (3:1) and restained with the fluorochrome Hoechst 33258 (23) for visualization of mouse centromeric regions.

At least 10 cells from each line were karyotyped. Mouse chromosomes and bands were identified according to the standard mouse karyotype recommended by the Committee on Standardized Genetic Nomenclature for Mice (24) and Nesbitt and Francke (25). CHO chromosomes were identified according to the standard karyotypes of Deaven and Petersen (26) and Worton et al. (27).

\section{RESULTS}

A Chinese hamster $\times$ mouse hybrid cell line containing one copy of mouse chromosome 14 was treated with $\gamma$-rays to generate rearrangements of mouse chromosomes. The different rearrangements of chromosome 14 observed in irradiated clones were compared with the patterns of $A d k, N p-1$, and $E s-10$ expression for the cytologic mapping of these three genes.

The hybrid used in this study, 7B31aTG2b-2, was formed by fusion of mouse CAK-B3 cells $(13,14)$ to ouabain-resistant $\mathrm{Hprt}^{-} \mathrm{Adk}^{-} \mathrm{CHO}$ cells. This hybrid contained serveral mouse chromosomes, includ- 
ing one copy of chromosome 14. A karyotype of this line is shown in Fig. 1. The mouse chromosome 14 is involved in a Robertsonian translocation with mouse chromosome 13 $[\mathrm{Rb}(13.14)]$. Consistent with the previous assignments of $A d k, N p-1$, and $E s-10$ to chromosome $14(10,11)$, the presence of the $\mathrm{Rb}$ (13.14) chromosome in hybrid cells correlated with the presence of the three mouse enzymes (unpublished observation).

7B31a-TG2b-2 was $\gamma$-irradiated to induce mouse chromosome breaks and rear- rangements. The mouse chromosomes should be relatively free to rearrange and segregate from irradiated cells, since mouse-hamster hybrids generally depend upon the hamster genome for survival $(28,29)$. Rearrangements resulting in the loss of segments of chromosome 14 should be reflected in the pattern of expression of $A d k, N p-1$, and $E s-10$ in the irradiated lines.

Isolation of Segregant Lines. Gammaray doses ranging from 500 to $2000 \mathrm{rad}$ were used to obtain segregant hybrid lines that

\section{MOUSE}

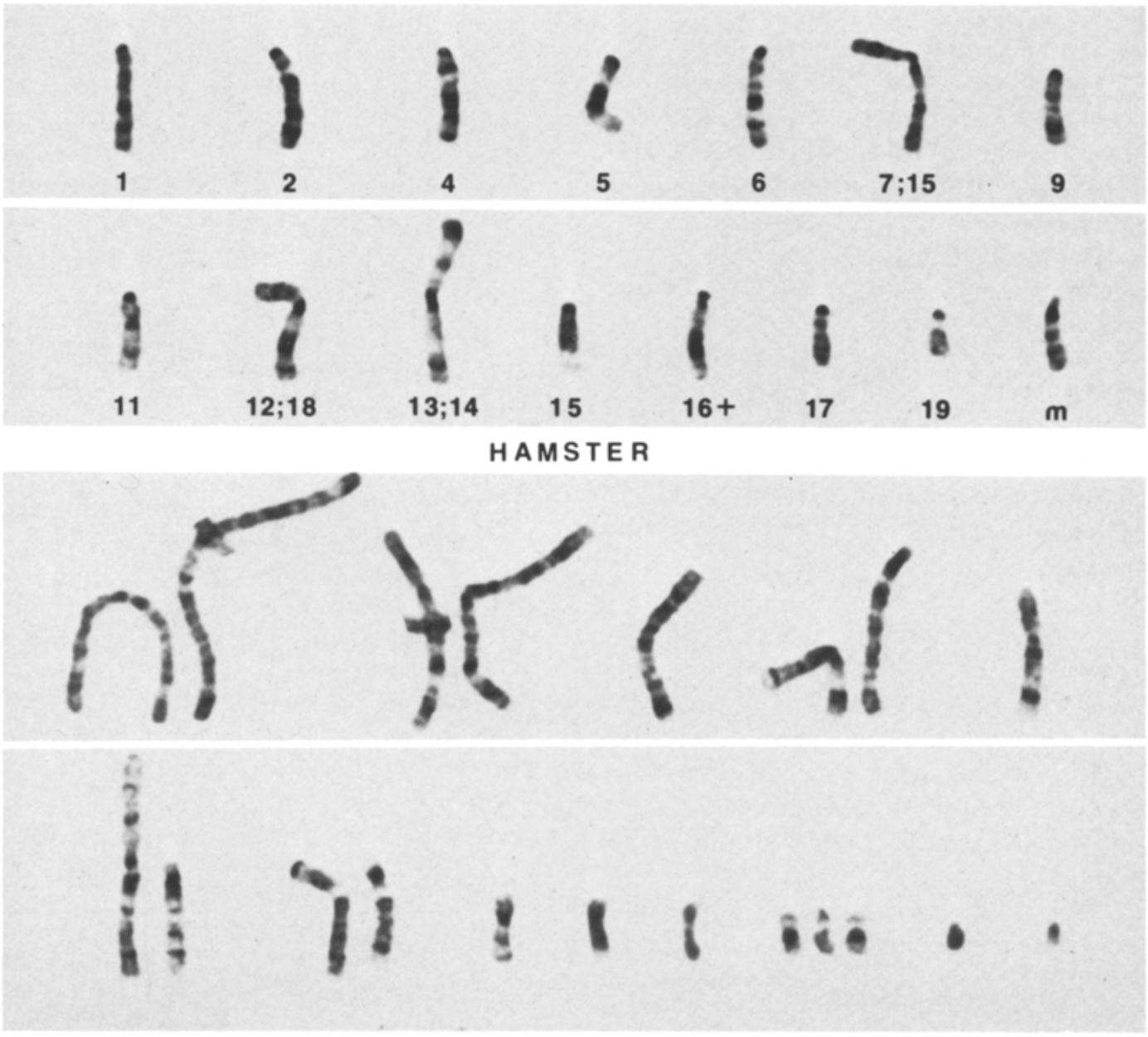

Fig. 1. 7B31a-TG2b-2 karyotype. The mouse chromosomes in this hybrid line are identified at the top of the figure and the hamster chromosomes are arranged at the bottom. The $16+$ chromosome is present in the parental mouse CAK-B3 line. The mouse marker, $\mathrm{m}$, appears to be derived from a mouse chromosome 18 or $X$. 
expressed one or two, but not all three of the genes on chromosome 14. Clones were isolated from the $500 \mathrm{R}, 750 \mathrm{R}$, and $1000 \mathrm{R}$ groups under selective as well as nonselective conditions; $2000 \mathrm{R}$ clones were isolated only in the absence of selection. Toyocamycin, an adenosine analog that becomes toxic when phosphorylated by $\operatorname{ADK}(30,31)$, was used to select clones that had alterations of chromosome 14. Since an ADK-deficient CHO line was used to form 7B31a-TG2b-2, the selection was specific for loss of the mouse enzyme.

A total of 172 irradiated cell lines was analyzed. The vast majority of the nonselected lines retained espression of $A d k, N p-I$, and $E s-10$. Two of the nonselected and 15 of the toyocamycin-selected lines simply lost all three of the chromosome 14 markers. The numbers and frequencies of clones in which only one or two of the markers were lost are listed in Table 1. The frequency of these segregant clones increased with the $\gamma$-ray dose received.

The phenotypes of the 36 segregants are listed in Table 2. Four different phenotypic classes, A, B, C, and D, were obtained. A predominance of class $\mathrm{B}$ segregants $\left(\mathrm{ADK}^{-}\right.$ $\mathrm{NP}-1^{+}$ES- $10^{+}$) was observed because a high proportion of the toyocamycin-selected lines were of this type. Only four of the six possible

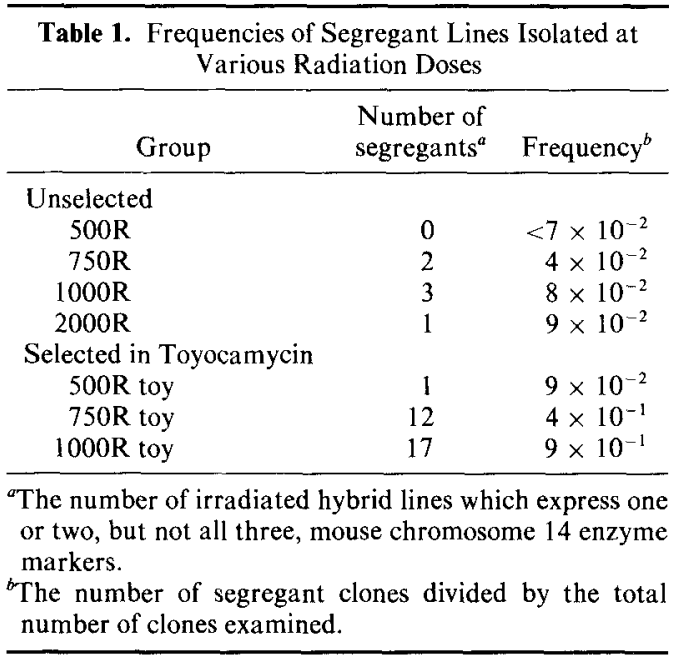

\begin{tabular}{ccccc}
\hline \multicolumn{4}{c}{ Table 2. Segregant Phenotypes } \\
\hline \multirow{2}{*}{\begin{tabular}{c} 
Segregant $\begin{array}{c}\text { Mouse enzyme expression } \\
\text { class }\end{array}$ \\
\cline { 2 - 5 }
\end{tabular}} & ADK & NP-1 & ES-10 & $\begin{array}{c}\text { Number of } \\
\text { clones }\end{array}$ \\
\hline A & + & - & - & 2 \\
B & - & + & + & 29 \\
C & + & + & - & 3 \\
D & - & - & + & 2 \\
\hline
\end{tabular}

segregant classes were observed; no clones were characterized in which NP-1 had segregated from both ADK and ES-10.

Chromosome Analysis. In order to characterize the mouse chromosome rearrangements induced by $\gamma$-irradiation, we analyzed the karyotypes of 12 of the segregant hybrid lines. These included all of the class A, $C$, and D segregants and five of the class $B$ segregants. One class B segregant, 750R toy $12 \mathrm{a}$, was composed of a mixture of cells with two different karyotypes. This line was subcloned, and clones of each chromosome type (750R toy $12 \mathrm{a}-1 \mathrm{~b}$ and $750 \mathrm{R}$ toy $12 \mathrm{a}-3 \mathrm{a}$ ) were isolated.

Several different types of rearrangements of chromosome 14 were identified among the segregants: four segregants had translocations; one line had a paracentric inversion; deletions of part of chromosome 14 were seen in five segregant lines; and one segregant, 750R 4a, had a complex rearrangement involving a translocation and an unstable dicentric derivative of chromosome 14 . (750R 4a will not be described further.) Two lines had no detectable abnormalities of chromosome 14 .

The translocations and the inversion of mouse chromosome 14 observed in the irradiated hybrid lines are shown in Fig. 2. Three of the four translocations (Fig. 2A-C) involved exchanges between chromosomes 14 and hamster chromosomes; the other translocation segregant (Fig. 2D) had a segment of mouse chromosome 14 translocated to mouse chromosome $\mathrm{Rb}(7.15)$. The inversion, as shown in Fig. $2 \mathrm{E}$, was a paracentric inversion in the chromosome $14 \mathrm{arm}$ of the $\mathrm{Rb}$ (13.14) metacentric chromosome. 


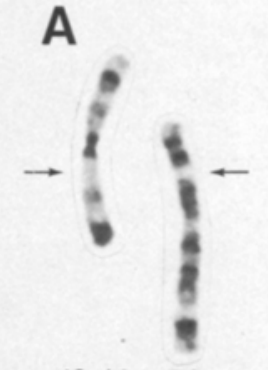

$13: 14 \quad Z 4$

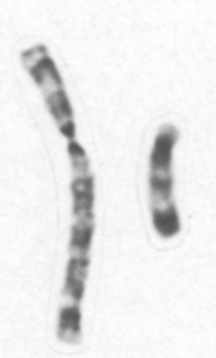

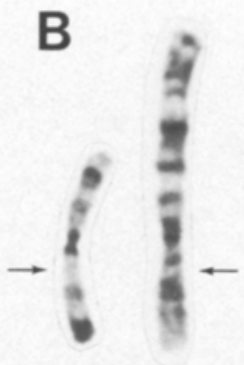

$13 ; 14 \quad Z 2$

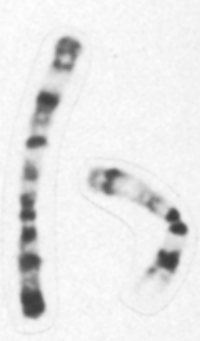

(2.

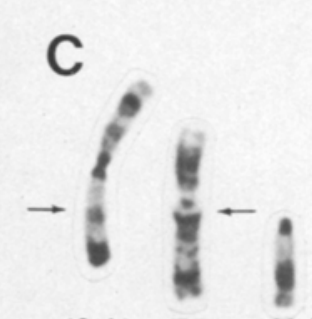

$13 ; 14 \quad Z 7 \quad 16+$

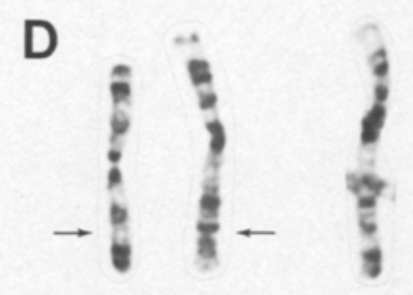

$13 ; 14 \quad 7 ; 15$

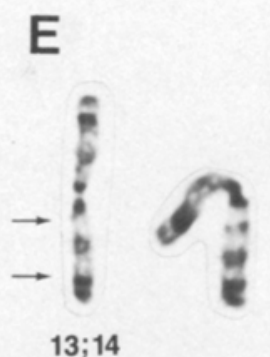

Fig. 2. Gamma-ray-induced translocation (A-D) and inversion (E) derivatives of mouse chromosome 14. The rearranged $\mathrm{Rb}(13.14)$ chromosomes from each line are on the right adjacent to examples of normal chromosomes from unirradiated cells. Arrows indicate the rearrangement breakpoints on the normal chromosomes. The Rb(13.14) chromosomes are oriented with the chromosome $14 \mathrm{arm}$ down. (A) $750 \mathrm{R}$ toy $12 \mathrm{a}-1 \mathrm{~b}$. Both reciprocal translocation products are shown next to the original $\mathrm{Rb}(13.14)$ and hamster $\mathrm{Z4}$ chromosomes. (B) 1000R toy 2a. The reciprocal translocation products resulting from a translocation between mouse 14 and hamster $\mathrm{Z} 2$ were both retained in the line. (C) $2000 \mathrm{R} 9 \mathrm{~b}$. The translocation in this line involved three chromosomes, hamster $\mathrm{Z} 7$ and the two mouse chromosomes, $\mathrm{Rb}(13.14)$ and $16+$. The terminal region of chromosome 14 was absent from this line. (D) 1000R 9. A translocation between the two mouse chromosomes $\mathrm{Rb}(13.14)$ and $\mathrm{Rb}(7.15)$ took place in this line. The centromere proximal portion of chromosome 14 was absent. (E) $750 \mathrm{R}$ toy $11 \mathrm{a}$. Inversion chromosome.

The rearrangements observed in three of these five lines, $750 \mathrm{R}$ toy $12 \mathrm{a}-1 \mathrm{~b}, 1000 \mathrm{R}$ toy $2 \mathrm{a}$, and $750 \mathrm{R}$ toy $11 \mathrm{a}$, had similar features (Fig. 2A, B and E, respectively). The entire chromosome 14 appeared to be retained in these lines; each had a chromosome break in the same region; and each was a class B segregant. This pattern suggested that the mouse $A d k$ gene might be located at the site of these chromosome breaks. Localization of the $A d k$ gene to this region of the chromosome was supported by the results of analysis of irradiation-induced deletion chromosomes.

Deletions were the most common type of rearrangement of chromosome 14 seen among the karyotyped segregants; they were included in each of the four segregant classes. The rearranged $\mathrm{Rb}(13.14)$ chromosomes from the 

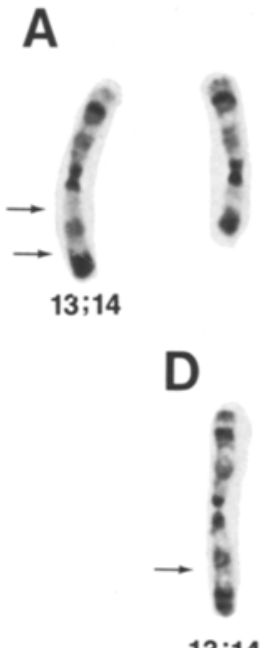
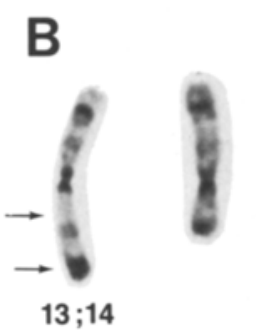
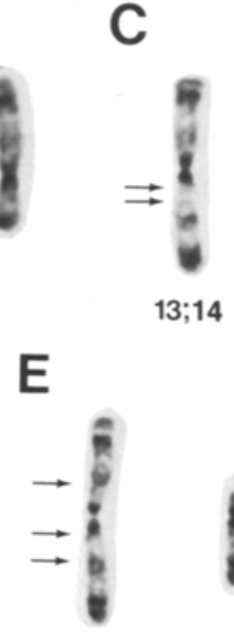

$13 ; 14$

Fig. 3. Gamma-ray-induced deletion derivatives of mouse chromosome 14. Deletion chromosomes are on the right, adjacent to labeled examples of normal $\mathrm{Rb}(13.14)$ chromosomes with the deletion breakpoints indicated. The $\mathrm{Rb}$ (13.14) chromosome is oriented with the chromosome 14 down. (A) 750R 20b. (B) 1000R 8. (C) 750R toy 3a. (D) 1000R 4. (E) $750 \mathrm{R}$ toy $9 \mathrm{a}$.

five deletion segregant lines are shown in Fig. a terminal deletion of chromosome 13 (Fig. 3. Four of the five deletions were interstitial; 1000R 4 appeared to have a terminal deletion (Fig. 3D). One line with an interstitial deletion of chromosome 14 (750R toy 9 a) also had

$3 \mathrm{E})$.

Two of the class B segregants had no cytologically detectable changes in mouse chromosome 14 . These lines presumably car-

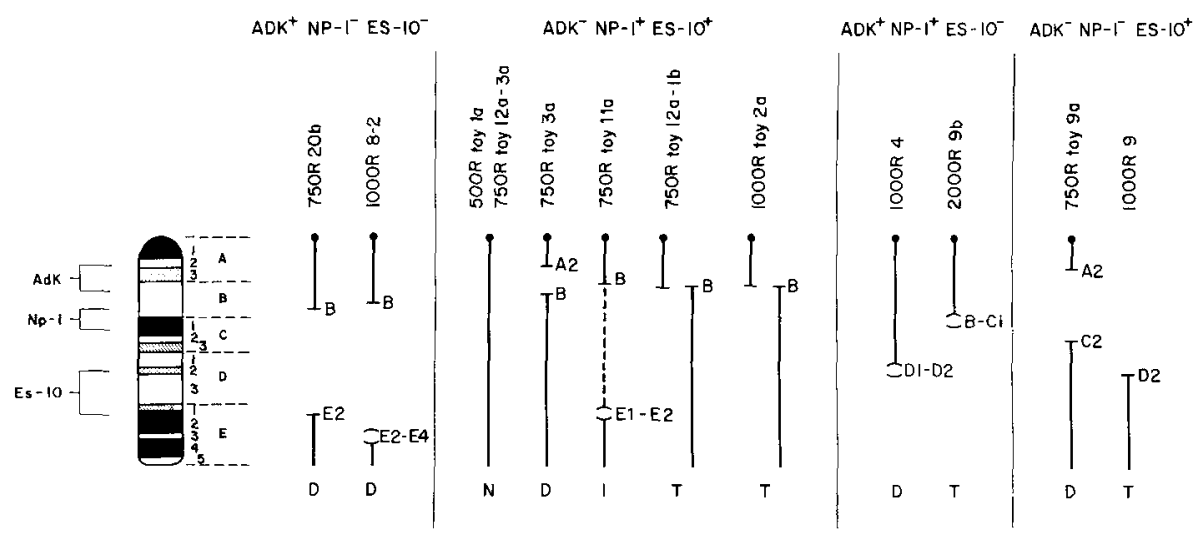

Fig. 4. Diagrams of the various rearrangements of mouse chromosome 14 in each of the segregant hybrid lines that were karyotyped. For those breakpoints that could not be localized to specific bands, parentheses indicate the region within which the breakpoint lies. The inverted segment is illustrated with a broken line. The letters at the bottom of the chromosome figures indicate the types of rearrangements which took place: $D$, deletion; $T$, translocation; I, inversion; $\mathrm{N}$, no change. The segregants are grouped together by phenotypic class. The regions of chromosome 14 to which the $A d k, N p-1$, and $E s-10$ genes were assigned, based on these overlapping rearrangements, are indicated on the idiogram at the left [adapted from Nesbitt and Francke (25)]. 
ry small deletions or point mutations of chromosome 14 near the $A d k$ gene.

Cytological Localization of Adk, Np-1, and ES-10. In order to map the $A d k, N p-1$, and $E s-10$ genes cytologically, we correlated the different chromosome 14 rearrangements with the expression patterns of these enzymes in the various segregant lines. Diagrams of each derivative $\mathrm{Rb}(13.14)$ chromosome characterized are shown in Fig. 4.

The deletion in $750 \mathrm{R}$ toy $3 \mathrm{a}$ defined the critical region within which the $A d k$ gene must be located. This chromosome had the smallest deletion that resulted in the loss of ADK activity; it was missing band A3 and some material in the bordering A2 and B bands. Note that this region includes the breakpoint found in common between the two translocation segregants $(750 \mathrm{R}$ toy $3 \mathrm{a}$ and $750 \mathrm{R}$ toy $12 \mathrm{a}-1 \mathrm{~b}$ ) and the inversion segregant (1000R toy $2 \mathrm{a}$ ) discussed previously.

A comparison of the rearrangements in 2000R 9b $\left(\mathrm{NP}-1^{+}\right)$and 750R 20b (NP-1 ${ }^{-}$) defined the region in which the $N p-1$ gene is located. The two rearrangement breakpoints differed only by the small region indicated on Fig. 4, bands B to C1. All other segregants analyzed had rearrangements consistent with this location. A similar comparison between segregants 750R 20b and 1000R 9 localized the $E s-10$ gene to bands D2 to E2.

\section{DISCUSSION}

A mouse-hamster hybrid cell line was used to determine the order and the cytological locations of the mouse $A d k, N p-1$, and $E s-10$ genes on chromosome 14 . The order of these genes was determined to be centromere$A d k-N p-1-E s-10$ - terminus; $A d k$ was localized to bands A2 to B, $N p-1$ to the B to $\mathrm{C} 1$ region, and $E s-10$ to the region between D2 and E2 (see Fig. 4).

Analysis of the inversion segregant and the two translocation segregants which were $\mathrm{ADK}^{-}$and had breaks in this region of chromosome 14 suggested a more specific localiza- tion of $A d k$ to band B, just below A3. Since the complete chromosome appears to have been retained, the basis for ADK loss in these lines is not obvious. Gene inactivation at translocation breakpoints has been reported previously (32-35). It may be that the $A d k$ gene was actually disrupted by these chromosome breaks.

The cytological map assignments for $\mathrm{Np}$ 1 and $E s-10$ are consistent with the genetic map. $N p-1$ is $15.8 \pm 2.4 \mathrm{cM}$ from the centromere of chromosome 14 (12), and Es-10 is $10.2 \pm 1.9 \mathrm{cM}$ centromere-distal to $\mathrm{Np}-1$ (10). A comparision of the genetic and cytological maps of chromosome 14 can be seen in Fig. 5. The two maps are colinear, and there is a rough correspondence between the cytological and genetic map distances.

Gamma-rays effectively induced mouse chromosomal rearrangements in the hybrid cells. In addition to those described for chromosome 14 , rearrangements of other mouse chromosomes were frequently observed. The use of the Robertsonian fusion chromosome permitted the rearranged chromosome 14 to be identified easily, since the other arm usually remained unaltered.

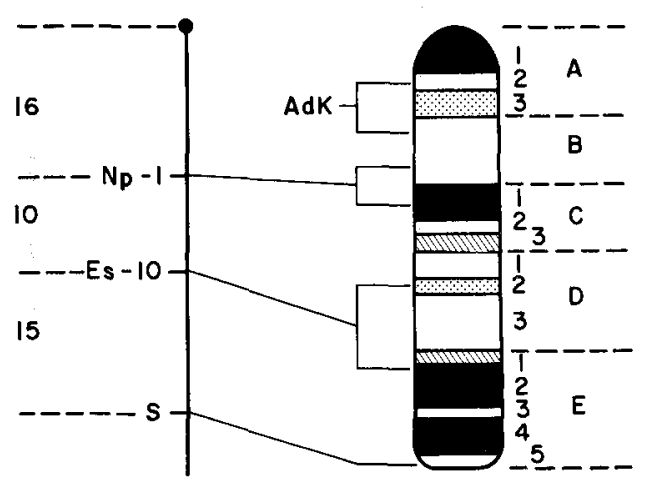

Fig. 5. A comparison of the genetic and cytological maps of mouse chromosome 14. The cytological locations of $A d k, N p-1$, and $E s-10$ determined in this study are indicated on the idiogram. The genetic map is from Roderick and Davisson (40). The numbers between the gene symbols indicate the approximate map distances between genes in centimorgans. The piebald locus, $s$, is the only other gene on chromosome 14 which has been mapped cytologically (41). 
The segregants analyzed in this study were independent isolates with unique karyotypes. All but two segregants had detectable chromosome 14 rearrangements. The two hybrids with apparently normal chromosomes were also of independent origin; they were selected from different subclones of the original hybrid line, and they had different karyotypes. A molecular analysis would be necessary to determine the mechanism of $A d k$ loss in these two lines.

Only a fraction of the $\mathrm{ADK}^{-} \mathrm{NP}-1^{+}$ ES $-10^{+}$(class B) segregants were karyotyped because of the large number with this phenotype (Table 2). The basis for the high frequencies of these segregants in the toyocamycinselected groups (Table 1) is unclear. A higher frequency of ADK - NP-1 - ES-10 clones, which had simply lost the entire chromosome, would have been expected, since loss of the $\mathrm{Rb}(13.14)$ chromosome was observed in unirradiated hybrids subjected to selection in toyocamycin (unpublished observation). One possible explanation for the high frequency of clones with chromosomal rearrangements is that the region including the $A d k$ locus is a hot spot for $\gamma$-ray-induced chromosome breaks. Nonrandom distributions of chromosome breaks following treatment with ionizing radiation have been observed previously (3638 ). Our data suggest a preference for chromosome breakage in band $\mathrm{B}$; in addition to the toyocamycin-selected segregants with breaks in band $\mathrm{B}$, two or three unselected segregants had breaks in this band. However, this is a biased sample of irradiated lines. In order to determine whether band $\mathrm{B}$ is a preferred site for $\gamma$-ray induced chromosome breakage, it would be necessary to karyotype random lines.

Another possible explanation for the high frequencies of class B segregants in the toyocamycin-selected groups is that cells that retain some portion of the $\mathrm{Rb}(13.14)$ chromosome may have a selective growth advantage. Since one hamster chromosome, Z5, was absent from 731a-TG2b-2, it is not surprising that a portion of the mouse genome may be required or preferred for optimal cell growth. Toyocamycin-selected clones that are $\mathrm{ADK}^{-}$ and continue to retain an undefined portion of $\mathrm{Rb}(13.14)$ may have a growth advantage. However, retention of a portion of $\mathrm{Rb}(13.14)$ cannot be a strict requirement, since loss of this chromosome from some lines has been observed (unpublished observation).

The irradiated hybrid lines produced in this study should be useful for regional localization of other mouse genes that have been assigned to other chromosomes. The hybrid line that was irradiated contained one and only one copy of most of the mouse chromosomes (Fig. 1); the other mouse chromosomes are likely to have been involved in rearrangements similar to those described for chromosome 14. Further development of the mouse biochemical map, emphasizing the locations of selectable markers like $A d k$, should define linkage groups valuable for the analysis of mitotic recombination and other genetic processes in cultured cells.

\section{ACKNOWLEDGMENTS}

We thank Zuhair Thalji and Joni Fleischman for technical assistance, and Dr. Eva Eves for providing the parental Chinese hamster $\times$ mouse hybrid cell line. This work was supported by National Institutes of Health grants GM24778, GM32098, and AI07099. Rosann A. Farber is the recipient of a National Institutes of Health Research Career Development Award.

\section{LITERATURE CITED}

1. Womack, J.E. (1982). Genet. Maps 2:286-293.

2. Francke, U., and Taggart, R.T. (1979). Proc. Natl. Acad. Sci. U.S.A. 76:5230-5233.

3. Francke, U., Lalley, P.A., Moss, W., Ivy, J., and Minna, J.D. (1977). Cytogenet. Cell Genet. 19:5784.

4. Fournier, R.E.K., and Moran, R.G. (1983). Somat. Cell Genet. 9:69-84.

5. Fournier, R.E.K., and Frelinger, J.A. (1982). Mol. Cell. Biol. 2:526-534. 
6. Burgerhout, W., van Someren, H., and Bootsma, D. (1973). Humangenetik 20:159-162.

7. Goss, S.J., and Harris, H. (1975). Nature 255:680684.

8. Kao, F.-T., Jones, C., and Puck, T.T. (1977). Somat. Cell Genet. 3:421-429.

9. Law, M.L., and Kao, F.-T. (1978). Somat. Cell Genet. 4:465-476.

10. Womack, J.E., Davisson, M.T., Eicher, E.M., and Kendall, D.A. (1977). Biochem. Genet. 15:347355.

11. Leinwand, L., Fournier, R.E.K., Nichols, E.A., and Ruddle, F.H. (1978). Cytogenet. Cell Genet. 21:7785.

12. Eppig, J.T., and Eicher, E.M. (1983). Genetics 103:797-812.

13. Farber, R.A., and Liskay, R.M. (1974). Cytogenet. Cell Genet. 13:384-396.

14. Eves, E.M., and Farber, R.A. (1981). Proc. Natl. Acad. Sci. U.S.A. 78:1768-1772.

15. Kao, F.-T., and Puck, T.T. (1968). Proc. Natl. Acad. Sci. U.S.A. 60:1275-1281.

16. Davidson, R.L., and Gerald, P.S. (1976). Somat. Cell Genet. 2:165-176.

17. Davidson, R.L., O'Malley, K.A., and Wheeler, T.B. (1976). Somat. Cell Genet. 2:271-280.

18. Littlefield, J.W. (1964). Science 145:709-710.

19. Baker, R.M., Brunette, D.M., Mankovitz, R., Thompson, L.H., Whitmore, G.F., Siminovitch, L., and Till, J.E. (1974). Cell 1:9-21.

20. Nichols, E.A., and Ruddle, F.H. (1979). Biochem. Genet. 17:127-132.

21. Peters, J., and Nash, H.R. (1978). Biochem. Genet. 16:553-569.

22. Chan, T.-S., Creagan, R.P., and Reardon, M.P. (1978). Somat. Cell Genet. 4:1-12.

23. Kozak, C.A., Lawrence, J.B., and Ruddle, R.H. (1977). Exp. Cell Res. 105:109-117.
24. Committee on Standardized Genetic Nomenclature for Mice (1972). J. Hered. 63:69-72.

25. Nesbitt, M.N., and Francke, U. (1973). Chromosoma 41:145-158.

26. Deaven, L.L., and Petersen, D.F. (1973). Chromosoma 41:129-144.

27. Worton, R.G., Ho, C.C., and Duff, C. (1977). Somat. Cell Genet. 3:27-45.

28. Kozak, C., Nichols, E.A., and Ruddle, F.H. (1974). J. Exp. Zool. 187:303-309.

29. Minna, J.D., Marshall, T.H., and Shaffer-Berman, P.V. (1975). Somat. Cell Genet. 1:355-369.

30. Bennett, L.L., Schnebli, H.P., Vail, M.H., Allan, P.W., and Montgomery, J.A. (1966). Mol. Pharmacol. 2:432-443.

31. Gupta, R.S., and Siminovitch, L. (1978). Somat. Cell Genet. 4:715-735.

32. Russell, L.B., and Bangham, J.W. (1961). Genetics 46:509-525.

33. Searle, A.G., Ford, C.E., and Beechey, C.V. (1971). Genet. Res. 18:215-235.

34. Hamerton, J.L., Mohandas, T., McAlpine, P.J., and Douglas, G.R. (1975). Cytogenet. Cell Genet. 14:346-348.

35. Cox, R., and Masson, W.K. (1978). Nature 276:629-630.

36. Seabright, M. (1973). Chromosoma 40:333-346.

37. Buckton, K.E. (1976). Int. J. Radiat. Biol. 29:475488.

38. Dutrillaux, B., Pequignot, E.V., Mouthuy, M., Antoine, J.L., Prod'homme, M., and Sportes, M. (1983). Mutat. Res. 119:343-350.

39. Burgerhout, W.G., Leupe-De Smit, S., and Jongsma, A.P.M. (1977). Cytogenet. Cell Genet. 18:267283.

40. Roderick, T.H., and Davisson, M.T. (1983). Mouse News Lett. 69:7-8.

41. Eicher, E.M., and Green, M.C. (1972). Genetics 71:621-632. 